\title{
Greenhouse Gas Emissions from Marine Tours: A Case Study of Australian Tour Boat Operators
}

\author{
T.A. Byrnes and J. Warnken \\ Centre for Aquatic Processes and Pollution (CAPP), Griffith University, \\ Australia
}

This paper estimates the overall and per capita energy costs and GHG contributions associated with tour boat operations in Australia, a country with a $35,000 \mathrm{~km}$ coastline and world class marine attractions. Using a comprehensive database of Australian tour boat operators, 145 face-to-face interviews or completed postal survey questionnaires and 45 in- situ audits, the overall GHG emissions for this industry sector was estimated conservatively at 70,000 tons $\mathrm{CO}_{2}$-e or $0.1 \%$ of the transport sector in Australia, the fastest growing sector in terms of GHG outputs. On average, this translated into an extra $61 \mathrm{~kg} \mathrm{CO}$-e per tourist if their travel itineraries included a trip on a boat with a diesel engine, or $27 \mathrm{~kg} \mathrm{CO}_{2}$-e for a trip on a boat with a petrol engine - the equivalent of a single person driving $140 \mathrm{~km}$ or $300 \mathrm{~km}$, respectively, in a standard passenger vehicle. Information obtained from Australian tour boat operators, however, indicated a range of technical and operational opportunities for reducing GHG emissions. In the light of Australia's anticipated growth in domestic and international visitors, the importance of reducing tour boat GHG outputs, is stressed.

Keywords: boats, tourism, greenhouse gas, tour boat operators

\section{Introduction}

Transport to and between destinations has been identified as tourism's major contributor to greenhouse gas (GHG) emissions. Travel by small to medium size tourist boats has received less attention than air, road, rail ferry and cruise ship transport. Many destinations, most notably those targeted by the mass tourism sector, are located in or near coastal environments. These areas provide opportunities for exploring adjacent waterways and marine environments. Recent trends in product diversification have helped to increase the demand for boat trips. The growing popularity of whale watching and dive tours are examples of the growth in this sector.

Marine transport has long been recognised as one of the major industry sectors responsible for producing large quantities of greenhouse gases (GHG) (Oberthur, 2003; Pisani, 2002), and other air pollutants such as nitrous oxides $\left(\mathrm{NO}_{x}\right)$ and sulphur dioxide $\left(\mathrm{SO}_{2}\right)$ (Lawrence \& Crutzen, 1999; Sinha et al., 2003). At the international level, emissions of GHG and pollutants from marine transport are largely associated with the use of large combustion (mostly diesel) engines operated on vessels navigating in international waters. The International Maritime Organisation (IMO) is currently addressing the release of air pollutants from these sources under Annex VI of MARPOL 73/78 (see 
www.imo.org). Its provisions have only come into force in 2005; however, GHG emissions have not yet been incorporated into this Annex.

At a national level in Australia, the increase in GHG emissions associated with transport is of major concern. Although the majority of these emissions across all types of GHGs (77.2 M tonnes $\mathrm{CO}_{2}$-e or $14.2 \%$ the national budget) were associated with road transport $(88 \%)$, marine transport or navigation contributed over-proportionally high amounts of Methane $\left(\mathrm{CH}_{4}\right)$, Carbon Monoxide $(\mathrm{CO})$ and Sulphur Dioxide $\left(\mathrm{SO}_{2}\right)$ (Year 2002, AGO, 2004). Marine transport within Australian territorial waters included shipping of raw materials, manufactured goods and products between major ports, commercial fishing operations, inner city public transport (river ferries), recreational activities, tourism, and a range of other minor activities. The contributions from each of these sub-sectors have not yet been quantified on a per sector basis. Activities in all the areas described above are likely to grow with a continuing increase in Australia's population, the migration to coastal areas and a greater diversity of recreational and life-style choices for local residents. Of all the marine transport sub-sectors in Australia, tourism is likely to be one of the fastest growing - fuelled by a strong growth in numbers of both domestic and international visitors over the past 10 years, and an ongoing diversification of Australia's tourism product. A good example of the more recently developed markets in the marine environment is the whale, dolphin and whale shark viewing sector with a growth rate of $23.5 \%$ between 2000 and 2003, generating 665,000 visitor nights in 2003 (BTR, 2004a, 2004b). The most popular activity of domestic tourists in Australia's coastal environments remained fishing, which was estimated to be a component of 5.78 million overnight trips (BTR, 2004a)

So far, there has been little interest in assessing the GHG emissions of the Australian tour boat industry. This lack of concern is somewhat surprising given that transport on water, particularly at high speed, can be very energy intensive (Becken \& Simmons, 2002) and, therefore, has the potential to add a significant amount of GHG emissions to the overall energy budget of a holiday trip. Tourism is one of Australia's major export industries, and the coastal and marine environments along its 35,000 km coastline provide key attractions for its tourism product. Furthermore, the tour boat industry itself appears to be particularly vulnerable to the effects of GHGs and climate change because of its dependence on:

- natural assets that are directly affected by rises in sea temperatures (reefs and fish stock);

- coastal infrastructure (ports, moorings, boat ramps) located directly at, or being part of, the land/ sea interface and, therefore, affected by rises in sea levels, as well as an increased intensity and perhaps frequency of tropical cyclones, storm surges, etc.; and

- periods of favourable and predictable weather conditions to allow operation of vessels under safe and stress-free (motion sickness) conditions.

The only sub-sector of the tourism industry that has so far attracted more detailed attention in regard to climate change is Australia's ski industry (Pickering et al., 2004; Pittock, 2003). This particular interest has possibly originated from the fact that several Australian ski resorts were considered marginal 
in regard to their natural snow cover and would face serious problems under the warmest climate change scenarios (Pittock, 2003).

Another reason for the lack of data and research in regard to the tour boat industry may lie in the diversity of this sector and the corresponding difficulties associated with obtaining reliable information at reasonable costs. In theory, marine tours can include anything from hiring a surfboard to cruising onboard a major ocean liner (Warnken \& Byrnes, 2004). For this study, surfboards, windsurfers and kite surfers were excluded: they resemble sporting equipment rather than vessels, and consume no fossil fuels. At the other extreme, ferries and ocean liners were excluded because their emissions were considered similar to large commercial vessels (except for solid wastes and sewage): they often operate in international waters as part of the major international shipping fleet and are, therefore, subject to treaties administered by IMO under MARPOL 73/78. Vessels used for ferry services forming part of a regional public transport network were also excluded from the work presented here, even though many of these vessels are also popular with tourists (e.g. Sydney Harbour ferries, New York City ferries, Hong Kong ferries, etc.).

The main objectives for this research were: to characterise the types of small to medium size tour boat operations in Australia's coastal environment; to estimate the overall and per capita GHG emissions for this sector; and to ascertain perceptions of tour boat operators (TBOs) about their contributions to GHG emissions and their ranking in regard to other impacts. Based on previous experiences with small to medium size enterprises (SMEs) in other sectors of the tourism industry (Warnken et al., 2004, 2005), information for this study was to be collected using a suite of methods ranging from face-to-face interviews, postal survey questionnaires and in-situ audits. Results from these investigations were to be used to highlight current problems with addressing GHG emissions in this industry sector and to explore how existing policy frameworks could be improved to encourage reductions in GHG emissions in the Australian tour boat industry.

\section{Methods}

The general lack of comprehensive data for the Australian tour boat sector required the work for this study be broken up into a set of consecutive tasks and phases. The first phase involved establishing a reliable database for all (or most) TBOs in Australia. This database was used to identify hotspots of tour boat operations and allowed a random selection of TBOs for the second phase, conducting initial face-to-face interviews and in-situ audits to fine tune and test the sampling instrument. The third and final phase involved the development and distribution of 750 postal survey questionnaires covering seven hotspot destinations in four Australian states (Queensland, New South Wales (NSW), Victoria (VIC) and Western Australia (WA) (Figure 1).

\section{TBO database}

Several online sources were queried for the listing of potential TBO addresses and phone numbers using categories such as diving, snorkelling, fishing, boat hire, cruises, etc.. Databases included telephone business directories (Yellow Pages), standard phone directories (White Pages), and the Australian Charter Guide 


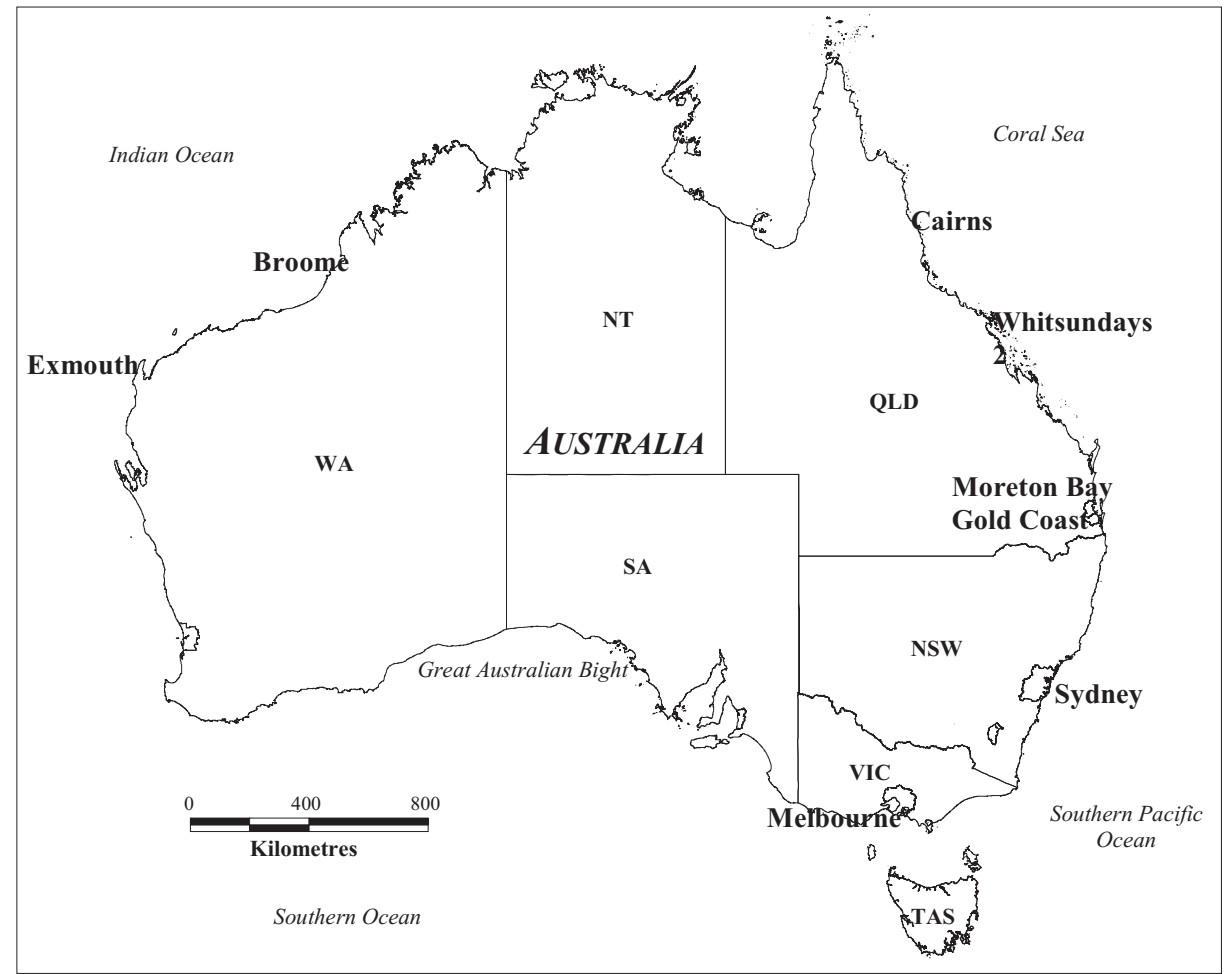

Figure 1 Location of study sites

and the 'Tour Finder' guide maintained by the Department of Conservation and Land Management (CALM) in WA. All entries in the resulting TBO database were standardised in regard to type and content of information provided in each field (e.g. street address, postcode, telephone number, etc.) and cross-checked for duplication of records based on names, phone numbers (including cellular phones) and addresses. The remaining records were grouped by postcodes, geo-coded to a current postcode layer available from CDATA 96 (ABS, 1997), and visually analysed for hotspots of tour boat activities.

\section{Face-to-face interviews}

A review of ship-sourced pollution legislation and literature relating to impacts of boats and larger vessels in general (Warnken \& Byrnes, 2003, 2004) provided the basis for preparing a questionnaire that tried to establish current views and practices of Australian TBOs in regard to their business and tour operations, vessel characteristics, general environmental impacts, and aspects relating to GHG emissions. Following an initial small-scale trial (Rainbow, 1999), 48 TBOs from seven hotspots were randomly selected and asked to participate in a 20-minute interview to be conducted at a location dictated by the interviewee. Despite considerable investment in time and resources, the willingness to participate in this research exercise remained low (Byrnes \& Warnken, 2003). 


\section{Postal survey}

The type and style of responses noted during face-to-face interviews were analysed and incorporated into a postal survey questionnaire reflecting the type of questions asked during face-to-face interviews. Wherever possible, operators were provided with tick boxes to facilitate providing information and to limit the time for completing the questionnaire to 25 minutes. The method used for the postal survey closely followed that outlined in Dillman (2000), including a survey questionnaire package with cover letter, etc.; a follow-up postcard; and (in case of a continuing non-response) a follow-up letter.

\section{In-situ audits}

Claims made by TBOs during face-to-face interviews were verified based on practices observed during incognito in-situ audits conducted prior to the interview. Audits were carried out using a checklist designed to focus on readily observable aspects of tour boat operations, thereby avoiding the risk of exposure of the investigator.

\section{Data compilation and analysis}

Information from each business or operator was entered into a set of interlinked databases. Entries in each field had to be standardised in order to reduce the number of categories. For example, small open tinnies ${ }^{1}$ and trailerable half-cabin cruisers or any other similar vessel, according to its hull type and configuration, dimensions, means of propulsion, engine details (inboard/ outboard, two or four stroke, petrol or diesel) were amalgamated into one category named 'Tinny/Half-Cabin'. Similar amalgamations or condensations were applied to other fields such as principal type of activity (fishing, diving, etc.).

\section{Results}

At first, 2998 business addresses of Australian TBOs were compiled from telephone directories and other databases. Returns from 750 questionnaires indicated that the initial database included some entries which referred to booking agents only, businesses that were no longer in operation, or operators under one or more business names. These were eliminated. Accordingly, the actual number of TBOs, operating at least one vessel, was estimated at 1476. An equal number $(\sim 30 \%)$ of these operators were listed with their postal address in NSW and Queensland, respectively.

For the seven study areas, 1505 TBOs were listed in the initial database. Of these, 799 were sampled by questionnaire or face-to-face interview; 49 supplied interviews, and half the remainder were randomly selected to receive postal questionnaires. Applying the same correction factor $(49.2 \%$ of actual TBOs in operation, see above) left approximately 400 TBOs that could be surveyed, or could have replied to the questionnaire. Overall, 145 operators responded to this study, either through participation in face-to-face interviews or a returned and, at least mostly, completed survey questionnaire. The overall response rate to the survey questionnaire and the 
face-to-face interviews was therefore estimated at $36 \%$, which equated to approximately $10 \%$ of all TBOs in Australia.

\section{Business characteristics}

In terms of business operations, the largest group of TBOs in this study (34.5\%) were those operating for 5-10 years. Almost three-quarters of operators considered their businesses to be small, employing usually one to five staff; $76 \%$ of TBOs operated only one or two vessels (Table 1). As expected, hire companies had relatively more vessels than other operators $\left(\chi^{2}=58.8,6 \mathrm{df}, p<0.0001\right.$ for businesses with 1, 2 or $>2$ vessels and 'others' excluded, Table 1).

Data from this research also indicated that some operators preferred a certain vessel type based on their principal type of activity. For example, more than $65 \%$ of fishing tour operators (28 out of 43 ) used fly-bridge cruisers or fishing boats / cruisers for their businesses and $62 \%$ of hire operators used tinnies / half-cabins or houseboats (Table 1). The use of purpose-built tourism vessels, such as dive boats and high-speed catamarans, was rare, at only $7 \%$.

Table 1 Vessel types and primary activities of Australian tourboat operators

\begin{tabular}{|c|c|c|c|c|c|c|}
\hline \multirow[b]{2}{*}{$\begin{array}{l}\text { Business } \\
\text { characteristics }\end{array}$} & \multicolumn{6}{|c|}{ Primary Activity } \\
\hline & Fishing & $\begin{array}{c}\text { Cruisel } \\
\text { sail }\end{array}$ & Hire & $\begin{array}{l}\text { Divel } \\
\text { snorkel }\end{array}$ & Other & Total \\
\hline Vessels 1 & $31 \quad(72 \%)$ & $27 \quad(69 \%)$ & $5 \quad(18 \%)$ & $16(57 \%)$ & $1 \quad(17 \%)$ & $80 \quad(55 \%)$ \\
\hline 2 & $11 \quad(26 \%)$ & $7 \quad(18 \%)$ & $2 \quad(7 \%)$ & $8 \quad(29 \%)$ & $2(33 \%)$ & $30 \quad(21 \%)$ \\
\hline$>2-5$ & - & $1 \quad(3 \%)$ & $6 \quad(21 \%)$ & $4 \quad(14 \%)$ & $3(50 \%)$ & $14 \quad(10 \%)$ \\
\hline$>5$ & $1 \quad(2 \%)$ & $4 \quad(10 \%)$ & $15 \quad(53 \%)$ & - & - & $20(14 \%)$ \\
\hline Total & $43(100 \%)$ & $39(100 \%)$ & $28(100 \%)$ & $28(100 \%)$ & $6(100 \%)$ & $145(100 \%)$ \\
\hline \multicolumn{7}{|l|}{ Vessel type } \\
\hline No Information & 4 & 2 & 3 & 6 & 1 & 16 \\
\hline $\begin{array}{l}\text { Twin Deck/ } \\
\text { Fly-Bridge Cruiser }\end{array}$ & 20 & 7 & 4 & 5 & 1 & 37 \\
\hline Sail boat & - & 16 & 3 & 4 & 1 & 24 \\
\hline Speed Boat & 8 & 6 & - & 4 & 1 & 19 \\
\hline Tinny / Half-Cabin & 3 & 2 & 11 & 1 & - & 17 \\
\hline $\begin{array}{l}\text { Fishing Boat/ } \\
\text { Cruiser }\end{array}$ & 8 & 4 & - & 1 & - & 13 \\
\hline $\begin{array}{l}\text { Houseboat/BBQ } \\
\text { Boat }\end{array}$ & - & 1 & 7 & - & - & 8 \\
\hline Dive Boat & - & - & - & 6 & - & 6 \\
\hline High-Speed Cat & - & 1 & - & 1 & 2 & 4 \\
\hline Other & - & - & 1 & - & - & 1 \\
\hline Total & 43 & 39 & 29 & 28 & 6 & 145 \\
\hline
\end{tabular}




\section{Vessel characteristics}

Most of the vessels used by TBOs in Australia were of a single hull configuration, on average 13 years old and $13 \mathrm{~m}$ in length overall (LOA) (Table 2). Smaller vessels (usually those less expensive and therefore less costly to replace) were not necessarily younger in age than the larger vessels. Tinnies and half-cabin cruisers, mostly around $5 \mathrm{~m}$ LOA, were on average 10 years old. Purpose-built tourism vessels, such as dive boats and high-speed catamarans, on the other hand, were, on average the largest and youngest vessels (Table 2).

Table 2 Vessel characteristics of Australian tour boat operators

\begin{tabular}{|c|c|c|c|c|c|c|c|c|c|c|c|c|c|}
\hline 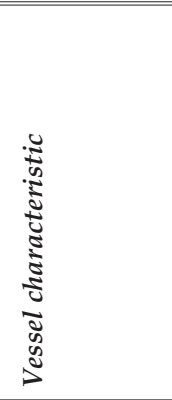 & & $\vdots$ & 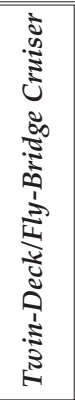 & $\begin{array}{l}\vec{\Xi} \\
\mathbb{D} \\
\stackrel{0}{\Xi} \\
\text { w }\end{array}$ & 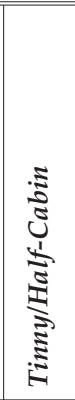 & $\begin{array}{l}\vec{\Xi} \\
\text { Dे } \\
\vec{\Xi} \\
\text { एँ } \\
\text { के }\end{array}$ & 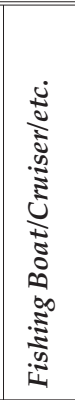 & 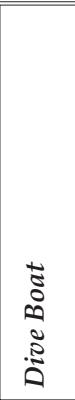 & 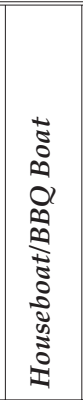 & 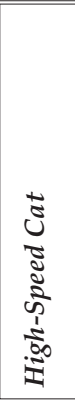 & 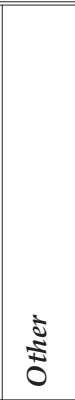 & $\begin{array}{l}\frac{*}{E} \\
0 \\
0\end{array}$ & $\partial^{\circ}$ \\
\hline \multicolumn{14}{|c|}{ Hull Configuration } \\
\hline INS & & 4 & - & - & - & - & - & - & - & - & - & 4 & 2.8 \\
\hline Mono-Hull & & 9 & 31 & 15 & 16 & 10 & 12 & 6 & 2 & - & 1 & 102 & 70.3 \\
\hline Double-Hull & & 2 & 6 & 9 & 1 & 7 & 1 & - & 6 & 4 & - & 36 & 24.8 \\
\hline \multirow[t]{2}{*}{ Tri-Hull } & & 1 & - & - & - & 2 & - & - & - & - & - & 3 & 2.1 \\
\hline & Total ${ }^{*}$ & 16 & 37 & 24 & 17 & 19 & 13 & 6 & 8 & 4 & 1 & 145 & 100.0 \\
\hline \multicolumn{14}{|c|}{ Length overall (m) } \\
\hline $0-<5$ & & 2 & - & 1 & 11 & - & - & - & - & - & - & 14 & 10.0 \\
\hline $5-<10$ & & 5 & 2 & 3 & 6 & 10 & 1 & 2 & 3 & - & - & 32 & 22.9 \\
\hline $10-<15$ & & 3 & 23 & 9 & - & 3 & 8 & - & 5 & - & - & 51 & 36.4 \\
\hline $15-<20$ & & - & 9 & 8 & - & 2 & 1 & 1 & - & 1 & - & 22 & 15.7 \\
\hline \multirow[t]{4}{*}{$\geq 20$} & & 3 & 2 & 3 & - & 3 & 3 & 3 & - & 3 & 1 & 21 & 15.0 \\
\hline & Total ${ }^{*}$ & 13 & 36 & 24 & 17 & 18 & 13 & 6 & 8 & 4 & 1 & 140 & 100.0 \\
\hline & Mean & 11.5 & 13.7 & 14.9 & 4.9 & 12.5 & 15.4 & 18.8 & 10.7 & 27.2 & 25.0 & 13.2 & - \\
\hline & $1 \mathrm{SE}$ & 1.9 & 0.6 & 1.1 & 0.3 & 1.8 & 1.8 & 3.6 & 1.16 & 4.4 & - & 0.6 & - \\
\hline \multicolumn{14}{|c|}{ Vessel age (yrs) } \\
\hline $0-<5$ & & 3 & 7 & 10 & 4 & 7 & 4 & 4 & 1 & 2 & - & 42 & 30.0 \\
\hline $5-<10$ & & 2 & 10 & 2 & 4 & 5 & 2 & - & 1 & 1 & - & 27 & 19.3 \\
\hline $10-<15$ & & 2 & 7 & 2 & 6 & 6 & - & 1 & 3 & - & - & 27 & 19.3 \\
\hline $15-<20$ & & 2 & 5 & 7 & 1 & 1 & 2 & - & 1 & 1 & - & 20 & 14.3 \\
\hline$\geq 20$ & & 4 & 8 & 3 & - & - & 5 & 1 & 2 & - & 1 & 24 & 17.1 \\
\hline Total $^{*}$ & & 13 & 37 & 24 & 15 & 19 & 13 & 6 & 8 & 4 & 1 & 140 & 100.0 \\
\hline Mean & & 16.3 & 13.3 & 12.8 & 9.7 & 8.1 & 19.3 & 8.0 & 14.4 & 7.5 & 70.0 & 13.0 & - \\
\hline $1 \mathrm{SE}$ & & 3.2 & 1.2 & 2.3 & 1.2 & 1.2 & 5.6 & 3.3 & 2.6 & 3.3 & - & 1.0 & - \\
\hline
\end{tabular}


Table 2 (contd) Vessel characteristics of Australian tour boat operators

\begin{tabular}{|c|c|c|c|c|c|c|c|c|c|c|c|c|c|}
\hline 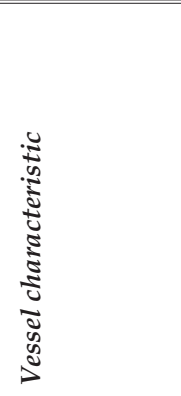 & & $\sum_{k}^{\infty}$ & 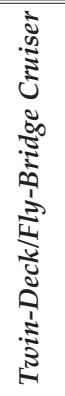 & $\begin{array}{l}\vec{I} \\
0 \\
0 \\
\tilde{\Xi} \\
\text { क }\end{array}$ & 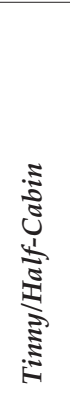 & $\begin{array}{l}\vec{J} \\
0 \\
0 \\
\tilde{\Xi} \\
\text { के } \\
\text { के }\end{array}$ & 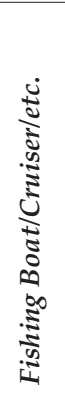 & 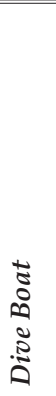 & $\begin{array}{c}\overrightarrow{0} \\
0 \\
0 \\
0 \\
0 \\
0 \\
0 \\
0 \\
0 \\
0 \\
0 \\
0 \\
0 \\
0 \\
0 \\
0\end{array}$ & 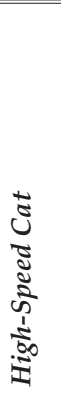 & $\frac{0}{\frac{7}{2}}$ & $\underset{⿱}{\frac{*}{5}}$ & $a^{0}$ \\
\hline $\begin{array}{l}{ }^{a} \text { Hull Config- } \\
\text { uration }\end{array}$ & $\begin{array}{l}\text { No. } \\
\text { Eng- } \\
\text { ines }\end{array}$ & & & & & & & & & & & & \\
\hline \multirow[t]{4}{*}{ Mono-Hull } & 1 & 5 & 14 & 15 & 5 & 15 & 4 & - & - & - & 1 & 59 & 41.3 \\
\hline & 2 & 4 & 17 & - & 5 & 1 & 8 & 2 & 4 & - & - & 41 & 28.7 \\
\hline & 3 & - & - & - & - & - & - & - & 2 & - & - & 2 & 1.4 \\
\hline & Total $^{*}$ & 9 & 31 & 15 & 10 & 16 & 12 & 2 & 6 & - & 1 & 102 & 71.3 \\
\hline \multirow[t]{5}{*}{ Double- Hull } & 1 & 2 & - & - & - & - & - & 5 & - & - & - & 7 & 4.9 \\
\hline & 2 & - & 6 & 8 & 7 & 1 & 1 & 1 & - & 4 & - & 28 & 19.6 \\
\hline & Total $^{*}$ & 2 & 6 & 8 & 7 & 1 & 1 & 6 & - & 4 & - & 35 & 24.5 \\
\hline & Mean & 1.3 & 1.6 & 1.3 & 1.6 & 1.1 & 1.7 & 1.4 & 2.3 & 2.0 & 1.0 & 1.5 & - \\
\hline & $1 \mathrm{SE}$ & 0.1 & 0.1 & 0.1 & 0.1 & 0.1 & 0.1 & 0.2 & 0.2 & 0.0 & - & 0.1 & - \\
\hline${ }^{\mathrm{b}}$ Diesel & & 8 & 36 & 19 & 8 & 1 & 13 & - & 4 & 4 & - & 93 & 64.1 \\
\hline \multirow[t]{2}{*}{ Petrol } & & 7 & - & 4 & 10 & 16 & - & 8 & 2 & - & - & 47 & 32.4 \\
\hline & Total $^{*}$ & 15 & 36 & 24 & 18 & 17 & 13 & 8 & 6 & 4 & 1 & 140 & 96.5 \\
\hline Engine & $0-5$ & 7 & 12 & 12 & 16 & 8 & 5 & 6 & 5 & 3 & - & 74 & 54.8 \\
\hline \multirow[t]{6}{*}{ Age (yrs) } & $\begin{array}{l}>5- \\
10\end{array}$ & 1 & 10 & 3 & 3 & 5 & 1 & 2 & 1 & 1 & - & 27 & 20.0 \\
\hline & $\begin{array}{l}>10- \\
15\end{array}$ & 1 & 4 & 1 & - & 3 & & - & - & - & - & 9 & 6.7 \\
\hline & $>15$ & 4 & 8 & 6 & - & - & 6 & - & - & - & 1 & 25 & 18.5 \\
\hline & Total $^{*}$ & 13 & 34 & 22 & 19 & 16 & 12 & 8 & 6 & 4 & 1 & 135 & 100.0 \\
\hline & Mean & 14.4 & 10.4 & 9.0 & 3.7 & 6.4 & 12.2 & 4.1 & 4.3 & 3.5 & 70.0 & 8.9 & - \\
\hline & $1 \mathrm{SE}$ & 4.8 & 1.3 & 1.6 & 0.4 & 0.8 & 2.6 & 0.9 & 0.9 & 1.2 & - & 0.9 & - \\
\hline
\end{tabular}

Note: INS = vessel characteristic information not supplied; ${ }^{*}=$ percentages of totals are given for the total number of responses for each variable measured; ' $3 \times$ 'INS' and $3 \times$ 'Tri-Hulls' excluded from this section of table, as such percentages calculated from a total of $137(95.8 \%)$ and not 143 $(100 \%){ }^{b} 4 \times{ }^{\prime}{ }^{\prime} N^{\prime}$ and $1 \times{ }^{\prime}$ Other' excluded from this section of table, as such percentages calculated from a total of $140(96.5 \%)$ and not $145(100 \%)$ 
Engine configuration on vessels used by Australian TBOs varied considerably. Overall, operators used engines from small two-stroke petrol outboard designs to large inbuilt, turbocharged two- and four-stroke diesel engines with claimed outputs of up to $1720 \mathrm{~kW}$. Table 2 attempts to summarise the more general aspects of engine types fitted to tourism vessels. Most double-hulled vessels had two engines whereas $58 \%$ and $40 \%$ of all mono-hulls had a single or double engine configuration, respectively. Close to two-thirds of all engines used by Australian TBOs were inboard four-stroke diesel engines, the remainder were mostly two- or four-stroke outboards.

An additional type of engine, used on larger tour boats, was generators operated to provide electricity. However, due to low numbers, the emissions from these combustion engines were not considered any further.

On average, marine engines used for propelling Australian tourism vessels were about four years younger than the hulls (Table 2). The highest turnover appeared to be with two-stroke (and to a lesser degree four-stroke) outboard engines. Many houseboats, tinnies/half-cabins and dive vessels (mostly semirigid inflatables) used outboard engines, which were on average younger than diesel engines in fly-bridge cruisers and sailboats (yachts). These results were not surprising as, from a technical and not uncommonly economical point of view, it is much easier to exchange an outboard engine than an inboard diesel engine. Further, changes to emission regulations for small spark ignition marine engines, under the US Clean Air Act 1990 (as amended) (EPA, 1996), prompted engine manufacturers to develop more fuel efficient two-stroke and, ultimately, four-stroke outboard designs. According to feedback during interviews, several operators preferred the modern two-stroke and four-stroke designs, mainly for their greater reliability.

\section{Tour characteristics}

Given that purchasing and maintaining a tourism vessel in Australia is quite expensive, it was surprising to discover that $50 \%$ of all operators who provided information stated that their vessel was in operation for only $50 \%$ of the year or less (Table 3). This low use group was dominated by cruise/ sail operators.

The majority of tours conducted were half day ( 3 to 6 hrs) or full day (6 to 12 hrs) trips. The most notable difference in trip duration for different types of tour boat activities were between fishing tours and cruises (sail or engine propelled). The majority of fishing trips lasted for between 6 and 12 hours, whereas cruises were usually less than 6 hours; the latter were also available for a more equal spread of passenger group sizes, whereas the number of customers on fishing trips rarely exceeded $10\left(\chi^{2}=47.7,6 \mathrm{df}, p<0.0001\right.$ for primary activities with 'zero to five', 'five to ten' or 'more than ten' guests / trip, 'others' excluded (Table 3).

\section{Calculations of GHG emissions}

The results presented above, and further pattern analyses (results not shown here), of the dataset demonstrated that Australian TBOs could not be grouped into homogeneous categories based on 'primary activity' type, vessel type or trip characteristics. Further, the relative proportion of different types of TBOs of the entire population of operators in Australia is unknown. Therefore, GHG emissions were estimated based on the following equations: 
Table 3 Trip characteristics of Australian tourboat operations

\begin{tabular}{|c|c|c|c|c|c|c|}
\hline \multirow[b]{2}{*}{$\begin{array}{l}\text { Tour } \\
\text { characteristics }\end{array}$} & \multicolumn{6}{|c|}{ Primary activity } \\
\hline & Fishing & $\begin{array}{c}\text { Cruisel } \\
\text { sail }\end{array}$ & Hire & $\begin{array}{c}\text { Divel } \\
\text { snorkel }\end{array}$ & Other & Total \\
\hline \multicolumn{7}{|l|}{ Boat Use $(\% / y r)$} \\
\hline $0-<25$ & $7(16 \%)$ & $11(28 \%)$ & $6(22 \%)$ & $2(7 \%)$ & $2(33 \%)$ & $28(20 \%)$ \\
\hline $25-<50$ & $16(37 \%)$ & $14(36 \%)$ & $11(41 \%)$ & $2(7 \%)$ & 0 & $43(30 \%)$ \\
\hline $50-<75$ & $11(26 \%)$ & $9(23 \%)$ & $4(15 \%)$ & $10(37 \%)$ & 0 & $34(24 \%)$ \\
\hline 75 & $9(21 \%)$ & $5(13 \%)$ & $6(22 \%)$ & $13(48 \%)$ & $4(66 \%)$ & $37(26 \%)$ \\
\hline Total & 43 & 39 & 27 & 27 & 6 & 142 \\
\hline Mean & 50 & 43 & 49 & 71 & 66 & 52 \\
\hline $1 \mathrm{SE}$ & 4 & 4 & 5 & 5 & 17 & 2 \\
\hline \multicolumn{7}{|c|}{ No. Guests per Average Length Trip } \\
\hline $0-<5$ & $14(33 \%)$ & $4(11 \%)$ & $14(58 \%)$ & $1(4 \%)$ & 0 & $33(24 \%)$ \\
\hline $5-<10$ & $22(51 \%)$ & $9(24 \%)$ & $5(21 \%)$ & $6(22 \%)$ & 0 & $42(30 \%)$ \\
\hline $10-<15$ & $4 \quad(9 \%)$ & $4(11 \%)$ & $4(17 \%)$ & $8(30 \%)$ & 0 & $20(14 \%)$ \\
\hline $15-<20$ & $2(5 \%)$ & $7(18 \%)$ & 0 & $2(8 \%)$ & $3(50 \%)$ & $14(10 \%)$ \\
\hline $20-<50$ & $1 \quad(2 \%)$ & $9(24 \%)$ & $1 \quad(4 \%)$ & $9(33 \%)$ & $2(33 \%)$ & $22(16 \%)$ \\
\hline 50 & 0 & $5(13 \%)$ & 0 & $1(4 \%)$ & $1(17 \%)$ & $7 \quad(5 \%)$ \\
\hline Total & 43 & 38 & 24 & 27 & 6 & 138 \\
\hline Mean & 8 & 31 & 7 & 22 & 60 & 19 \\
\hline $1 \mathrm{SE}$ & 1 & 6 & 1 & 4 & 33 & 3 \\
\hline \multicolumn{7}{|c|}{ Time Average Length Trip (hrs / trip) } \\
\hline $0-3$ & $1(2 \%)$ & $11(30 \%)$ & $8(33 \%)$ & $7(25 \%)$ & $2(33 \%)$ & $29(21 \%)$ \\
\hline $3-<6$ & $16(39 \%)$ & $16(43 \%)$ & $7(29 \%)$ & $8(29 \%)$ & $2(33 \%)$ & $49(36 \%)$ \\
\hline $6-<12$ & $24(59 \%)$ & $8(22 \%)$ & $5(21 \%)$ & $10(36 \%)$ & $2(33 \%)$ & $49(36 \%)$ \\
\hline 12 & 0 & $2(5 \%)$ & $4(17 \%)$ & $3(11 \%)$ & 0 & $9(7 \%)$ \\
\hline Total & 41 & 37 & 24 & 28 & 6 & 136 \\
\hline Mean & 7 & 10 & 20 & 18 & 4 & 12 \\
\hline $1 \mathrm{SE}$ & 0 & 5 & 7 & 8 & 1 & 2 \\
\hline
\end{tabular}

GHG fuel type $\left(\mathrm{CO}_{2}\right.$-e $)=\mathrm{FC}_{\text {fuel type }}\left(\mathrm{l} \mathrm{h}^{-1}\right) \times \mathrm{TD}_{\text {fuel type }}(\mathrm{h}) \times 0.6^{\mathrm{a}} \times \mathrm{V} /$ op fuel type $\times \mathrm{USE}_{\text {fuel type }}$ $(\% \times 0.01) \times 365 \times \mathrm{Ops}_{\text {fuel type }}(\%$ sample $\times 1476 \times 0.01) \mathrm{EF}_{\text {fuel type }}\left(\mathrm{kg} \mathrm{CO}_{2}\right.$-e l$\left.{ }^{-1}\right)$

where

$\mathrm{FC}=$ average fuel consumption stated by operators

$\mathrm{TD}=$ average trip duration 
$\mathrm{V} / \mathrm{op}=$ average number of vessels per operator

USE $=$ average percent use per annum

Ops $=$ number of operators

$\mathrm{EF}=$ emission factor (fuel cycle) for diesel and petrol combustion engines as recommended by the Australian Greenhouse Office AGO (2003)

Note: $\mathrm{a}=$ correction factor for turning off engines while stopped (or moored) at destination (one or several) based on estimations from observations during 45 in-situ audits.

$$
\mathrm{GHG}_{\mathrm{TBO}} \mathrm{sustralia}=\sum \mathrm{GHG}_{\text {fuel type }}
$$

Based on these equations, the overall GHG emissions for the Australian tour boat industry sector were estimated conservatively at 70,000 tonnes $\mathrm{CO}_{2}$-e or $0.1 \%$ of the transport sector in Australia, the fastest growing sector in terms of GHG outputs. Taking the average number of guests per trip into account, GHG emissions translated into an extra $61 \mathrm{~kg} \mathrm{CO}$-e per tourist if their travel itineraries included a trip on a boat with a diesel engine, or $27 \mathrm{~kg} \mathrm{CO}_{2}$-e for a boat with a petrol engine - the equivalent of a single person driving $140 \mathrm{~km}$ or $300 \mathrm{~km}$, respectively, in a standard passenger vehicle. At a first glance, these results seem surprising given that diesel engines are usually more fuel-efficient than petrol engines. In this context, however, the higher fuel consumption per tourist for diesel engines was largely attributable to vessels that combined the fuel efficiency of inboard diesel engines with a hull large and fast enough to take tourists further out to sea.

\section{Reducing GHG emissions}

When asked to consider the impacts of their vessel on coastal environments in an open-ended question, almost $51 \%$ of operators were of the opinion that their activities caused no impact. Of those who were aware of their potential impacts, 30 out of 71 mentioned engine emissions, mostly in the form of small fuel spillages and oil leaks (Table 4).

Table 4 Operators' perceptions related to engine emissions and other impacts associated with using a tourism vessel in coastal environments

\begin{tabular}{|c|c|c|c|c|c|c|}
\hline \multirow[b]{2}{*}{$\begin{array}{l}\text { Type of vessel } \\
\text { impact perceived } \\
\text { by operator }\end{array}$} & \multicolumn{6}{|c|}{ Primary activity } \\
\hline & Fishing & $\begin{array}{c}\text { Cruisel } \\
\text { sail }\end{array}$ & Hire & $\begin{array}{c}\text { Divel } \\
\text { Snorkel }\end{array}$ & Other & Total \\
\hline No impact & $24 \quad(56 \%)$ & $20 \quad(69 \%)$ & $16(83 \%)$ & $10 \quad(58 \%)$ & $4 \quad(67 \%)$ & $74 \quad(51 \%)$ \\
\hline \multicolumn{7}{|l|}{ Impact } \\
\hline Engine Emissions & $9 \quad(21 \%)$ & $7 \quad(23 \%)$ & $9 \quad(10 \%)$ & $5 \quad(29 \%)$ & - & $30 \quad(21 \%)$ \\
\hline Other & $10 \quad(23 \%)$ & $12 \quad(8 \%)$ & $4 \quad(7 \%)$ & $13(14 \%)$ & $2(33 \%)$ & $41 \quad(28 \%)$ \\
\hline Total & $43(100 \%)$ & $39(100 \%)$ & $29(100 \%)$ & $28(100 \%)$ & $6(100 \%)$ & $145(100 \%)$ \\
\hline
\end{tabular}

A slightly different picture could be obtained when operators were asked to rank the severity of potential impacts of different aspects of operating a vessel on 
a scale of 1 to 10 (the latter representing the highest impact). Under these circumstances, TBOs ranked engine emissions second highest after impacts associated with the release of, until then, mostly untreated raw sewage from marine toilets and galleys (Table 5).

Both the survey questionnaire and the face-to-face interviews provided TBOs with an opportunity to comment on any aspect of their operations that they believed was of concern or should be addressed. None of these comments contained any remarks on GHG emissions or the potential effects of climate change on the day-to-day operations of TBOs in Australia.

\section{Discussion}

\section{Accuracy of $\mathrm{CO}_{2}$-e emission estimates}

All data obtained for this study were derived from operators, or the supply side of the tour boat market, and could not be verified against information collected from the demand side, i.e. overall visitor numbers for marine tour activities contained in the International Visitor Survey (IVS) or National Visitor Survey (NVS) conducted by the Australian Bureau of Tourism Research (BTR). The data collected by the BTR focus on activities (e.g. going fishing) and do not differentiate between ways in which this activity was conducted, for example fishing from the shore or beach versus fishing from a private vessel or fishing on a commercial tour. Another compounding factor associated with the BTR data is that many operators offered several activities on a single trip. Whale shark operators in Western Australia usually incorporated a guided dive tour, either after all their customers had been provided with the opportunity to swim with a whale shark, or, in case no whale sharks were spotted on that day, as an alternative programme. Similar scenarios were observed for operators on the Great Barrier Reef, who often combined snorkelling and scuba dives in one trip.

It must be further acknowledged that the information provided by operators (notably with the questionnaire) was sometimes inconsistent or occasionally conflicting. For example, some operators considered themselves as a small business with three staff, whereas other operators with the same number of staff considered themselves to be a medium-sized enterprise. Another potential source of error was the number of days or the time period that operators considered their vessel(s) to be out at sea and in use. Some may have taken adverse weather conditions or periods for maintenance into consideration, while others may have just reflected on their usual weekly business activities. A third factor limiting the accuracy of GHG emissions calculated for this study was the use of two-stroke diesel and petrol engines (no conversion factors could be obtained for predicting the amount of $\mathrm{CO}_{2}$-e for these types of combustion engines).

Using data from fuel purchases at marinas and boat harbours would have quite possibly provided estimates with similar (if not greater) levels of uncertainties, as many TBOs share fuelling stations with other vessel operators (e.g. users of recreational vessels of similar size and commercial fishermen). TBOs with boats propelled by small outboard engines sometimes purchase fuel from road petrol stations to avoid additional charges or higher costs for fuel sold at marine 


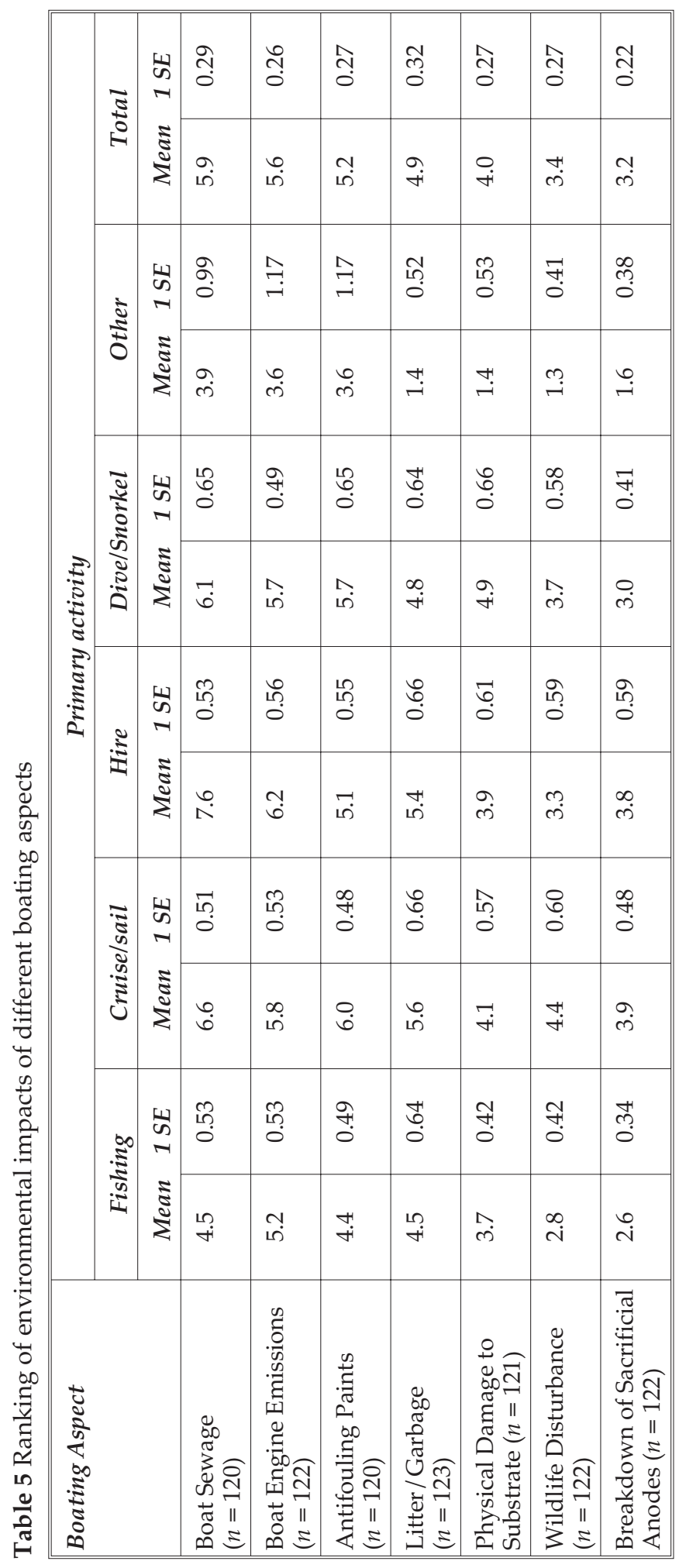


refuelling stations. Again, the degree to which these practices exist among TBOs is currently unknown and would have caused estimates, based on fuel use, to be equally speculative.

A possible alternative for future work in this area could involve an assessment of monthly or quarterly fuel bills paid by a representative set of operators for each tour boat type (either based on hull characteristics or operational aspects) and subsequent extrapolation based on an updated tour operator database. Access to relevant data sources, in this case fuel bills, depends largely on the willingness of operators to collaborate and, based on experiences with this work (Byrnes \& Warnken, 2003) and the sensitivities in other sectors of the tourism industry about the release of potentially sensitive commercial information (Warnken et al., 2004b), it may be quite difficult to find sufficient support from operators for this type of study.

\section{Reduction of GHG emissions}

Even though the actual overall amount of GHG emissions of Australian TBOs represents only $0.1 \%$ of emissions associated with transport activities across Australia, there appears to be a number of practices that lead to unnecessary waste of non-renewable fossil fuels and emissions of GHGs. At the technical level, a comparison of engine specifications and combinations of hull and engine designs of individual operators revealed that a number of operators used old, and possibly outdated, engines or combinations of engine/hull designs. Using a vessel equipped with two $485 \mathrm{~kW}$ engines, an average fuel consumption of $300 \mathrm{l} / \mathrm{hr}$ and an average of no more than 11 passengers per trip should become a practice that is strongly discouraged.

Data from this study also indicated that the majority of Australia's TBOs were ignorant regarding the potential for their operations to cause environmental impacts. Further, the idea that GHG emissions and climate change could affect day-to-day operations was non-existent among the operators surveyed for this study. This included larger companies which claimed to have internal environmental management systems in place and were accredited, or in the process of becoming accredited, as ecotour operators.

The lack of awareness about GHG emissions and climate change amongst Australian TBOs and possibly most of their domestic clients could be the result of Australia's arid, hot climate and its history of sometimes drastic climate changes triggered by oscillations of surface water temperatures in the southern oceans (El Niño Southern Oscillation [ENSO] effects). Although this might need further research, the colloquial term of 'another stinking hot summer' indicates that Australians have learned to accept extremes. This not only includes heatwaves and droughts but also rain events and flooding associated with tropical cyclones (particularly along the northern part of the continent, anywhere between Perth and northern NSW, see Pittock, 2003). Another difficulty with experiencing long-term changes in Australia's climate is that ENSO effects can be very localised and, therefore, allow only little or no direct comparison.

The following measures, all coordinated and facilitated by the Australian Greenhouse Office (AGO), could prevent many of the current ill-informed practices leading to the unnecessary use of non-renewable fossil fuels: 
- better communication of technical innovations/solutions between TBOs, naval architects and engineers;

- introduction of a fuel consumption based excise on operator permits; and

- small industry grants for upgrades of marine engines.

As indicated above, possibly the most encouraging aspect of marine tour operations appears to be the need for frequent replacement of engines. More modern engines are usually smaller and lighter than the ones they replace and, in light of the usually very tight engine compartments on small to medium tourist vessel, provide the extra space and weight savings required for adding external emission control devices (e.g. particulate removal filters). However, the trade-offs between the additional GHG emissions resulting from the energy used to manufacture the cleaner replacement engines would need to be carefully considered in conjunction with any potential reductions in GHG emissions to be achieved by replacing the older, less GHG friendly engines.

In summary, work from this project has provided some estimates for GHG emissions and contributions of Australian TBOs to global climate change. These results have also demonstrated that there is a considerable lack of data and awareness of impacts in general, and GHG emissions in particular, and that it would be prudent to assume that this level of information would be sufficient to design industry-specific measures for reducing fuel consumption and subsequently GHG emissions. Ultimately, in the light of Australia's anticipated growth in domestic and international visitors, the Australian tour boat industry needs to take its current GHG outputs seriously and develop measures to reduce fuel consumptions and engine emissions in order to maintain overall GHG emissions at present levels.

\section{Acknowledgements}

This work would not have been possible without financial support provided by the Cooperative Research Centre for Sustainable Tourism.

\section{Correspondence}

Any correspondence should be directed to Dr Jan Warnken, Centre for Aquatic Processes and Pollution (CAPP), Griffith University, Gold Coast PMB 50 GCMC, Qld 9726 (j.warnken@griffith.edu.au).

\section{Note}

1. The Australian term 'tinnies' generally refers to open aluminium boats, 3-6 metres in length, with outboard engines.

\section{References}

ABS (Australian Bureau of Statistics) (1997) CDATA96 (electronic GIS database for 1996 census data). Canberra, Australia.

AGO (Australian Greenhouse Office) (2003) AGO factors and methods workbook, version 3 On WWW at http: / / www.greenhouse.gov.au/challenge/tools / workbook / index.html. Accessed 05.08.04.

AGO (Australian Greenhouse Office) (2004) National Greenhouse Gas Inventory 2002. Canberra: Australian Greenhouse Office.

Becken, S. and Simmons, D.G. (2002) Understanding energy consumption patterns of tourist attractions and activities in New Zealand. Tourism Management 23, 343-54. 
BTR (Bureau of Tourism Research) (2004a) National visitor survey, overnight trips 2003 (electronic data). BTR, Canberra.

BTR (Bureau of Tourism Research) (2004b) International visitor survey, stopover state and leisure activities 2003 (electronic data). BTR, Canberra.

Byrnes, T. and Warnken, J. (2003) Establishing best practice environmental management: Lessons from the Australian tour boat industry. In R.C. Buckley, C.M. Pickering and D. Weaver (eds) Nature Tourism, Land Management and Environment (pp. 111-22). Wallingford: CABI.

Dillman, D.A. (2000) Mail and Internet Surveys: The Tailored Design Method (2nd edn). New York: Wiley.

Lawrence, M.G. and Crutzen, P.J. (1999) Influence of $\mathrm{NO}<\mathrm{v}>\mathrm{x}<\mathrm{d}>$ emissions from ships on tropospheric photochemistry and climate. Nature 402 (6758), 167-70.

Oberthur, S. (2003) Institutional interaction to address greenhouse gas emissions from international transport: ICAO, IMO and the Kyoto Protocol. Climate Policy 3 (3), 191205.

Pickering, C.M., Goods, R. and Green, K. (2004) The Ecological Impacts of Global Warming: Potential Effects of Global Warming on the Biota of the Australian Alps. Report to the Australian Greenhouse Office (AGO), Canberra.

Pisani, C. (2002) Fair at sea: The design of a future legal instrument on marine bunker fuels emissions with the climate change regime. Ocean Development and International Law 33 (1), 57-76.

Pittock, B. (2003) Climate Change: An Australian Guide to the Science and Potential Impacts. Canberra: Australian Greenhouse Office (AGO).

Rainbow, J. (1999) Best practice environmental management for dive boat operators in Southern Queensland and Northern New South Wales. Honours Thesis, School of Environmental and Applied Sciences, Griffith University, Gold Coast.

Sinha, P., Hobbs, P.V., Yokelson, R.J., Christian, T.J., Kirchstetter, T.W. and Bruintjes, R. (2003) Emissions of trace gases and particles from two ships in the southern Atlantic Ocean. Atmospheric Environment 37 (15), 2139-48.

US EPA (Environmental Protection Agency) (1996) Final rule on 40 CFR 89,90,91. Federal Register 61 (194), 52087-169.

Warnken, J., Bradley, M. and Guilding, C. (2004a) Eco-resorts vs mainstream accommodation providers: An investigation of the viability of benchmarking environmental performance. Tourism Management 26, 367-79.

Warnken, J., Bradley, M. and Guilding, C. (2004) Exploring methods and practicalities of conducting sector-energy consumption accounting in the tourist accommodation industry. Ecological Economics 48, 125-41.

Warnken, J. and Byrnes, T. (2003) Small recreational and tourist vessels in inshore coastal areas: A characterisation of types of impacts. In R.C. Buckley, C.M. Pickering and D. Weaver (eds) Nature Tourism, Land Management and Environment (pp. 123-36). Wallingford: CABI.

Warnken, J. and Byrnes, T. (2004) Impacts of tourboats in marine environments. In R.C. Buckley (ed.) Environmental Impacts of Ecotourism (pp. 99-123). Wallingford: CABI. 